\title{
Does evidence support audiological internet-based interventions?
}

\author{
Eldré Beukes and Vinaya Manchaiah
}

A few recent studies have highlighted the true extent regarding the rising prevalence of hearing loss ${ }^{1}$, being the second most common impairment in a review investigating 310 diseases ${ }^{2}$. The impact of hearing loss is often not isolated and may co-occur with other distressing prevalent auditory conditions such as tinnitus and loss of vestibular function. The incidence of these conditions increases with age ${ }^{3-5}$, which is of concern due to the proportion of elderly people rising ${ }^{6}$. As these are chronic long-term conditions, ongoing management is required, adding both the healthcare and societal economic burden. For hearing loss alone, the resulting annual global costs are $\$ 750$ billion dollars (World Health Organization, Deafness and hearing impairment, 2018). Although interventions to address hearing loss, tinnitus, and vestibular disorders are cost-effective, provision of such services is hampered by factors such as a lack of resources ${ }^{7}$, evidence-based treatments, and limited hearing healthcare (HHC) professionals ${ }^{8}$. Uptake of interventions is further complicated by multiple factors surrounding accessibility (in terms of location and time), cost, and barriers surrounding engagement and compliance ${ }^{9}$.

Internet-based interventions (IBI) have emerged as an approach to address these barriers by offering accessibility and affordability of HHC services ${ }^{10}$ that encourage self-management and engagement ${ }^{11}$. They are attractive due to providing great flexibility as either a replacement or supplement to routine care. They can also be provided with or without guidance (i.e., professional support). Perhaps their most attractive aspect is that they can be used as a shared global resource, being based online and not at a specific geographical location. Despite the advantages of IBI in terms of provision of hearing-related rehabilitation, emphasize needs placed on their evidence base. HHC provision should always prioritize clinically effective treatments. To investigate the evidence base for IBI for hearing loss, tinnitus and vestibular disorders, Beukes et al. (2019) ${ }^{12}$ undertook a systematic review. This review is important, as it is the first to summarize the evidence base for hearing-related IBI. What set this systematic review apart was its comprehensiveness. It reviewed IBI targeting hearing loss, tinnitus and vestibular difficulties. It furthermore focused on identifying not only their primary effects, but also the secondary and long-term effects. To improve the quality of the evidence, only randomized controlled trials were included.

\section{Main Findings}

In this review, 15 studies, amounting to data from 1,811 participants, were suitable for inclusion. The majority (12 studies) were efficacy trials (i.e., tested IBI in controlled conditions) and three were effectiveness studies (i.e., tested IBI in the "real" world conditions). The studies included in the review were undertaken in Sweden, the UK, and Germany. All the Internet intervention arms provided guidance except for the vestibular rehabilitation Internet intervention. There was little overlap in approach in terms of the range of interventions (see Figure 1) and comparators (see Figure 2) used, except for consistent use of Cognitive Behavioral Therapy (CBT) for tinnitus. Comparison of the main finding for each type of IBI is summarized in Table 1.

\section{Figure 1: Range of Internet-based interventions used}




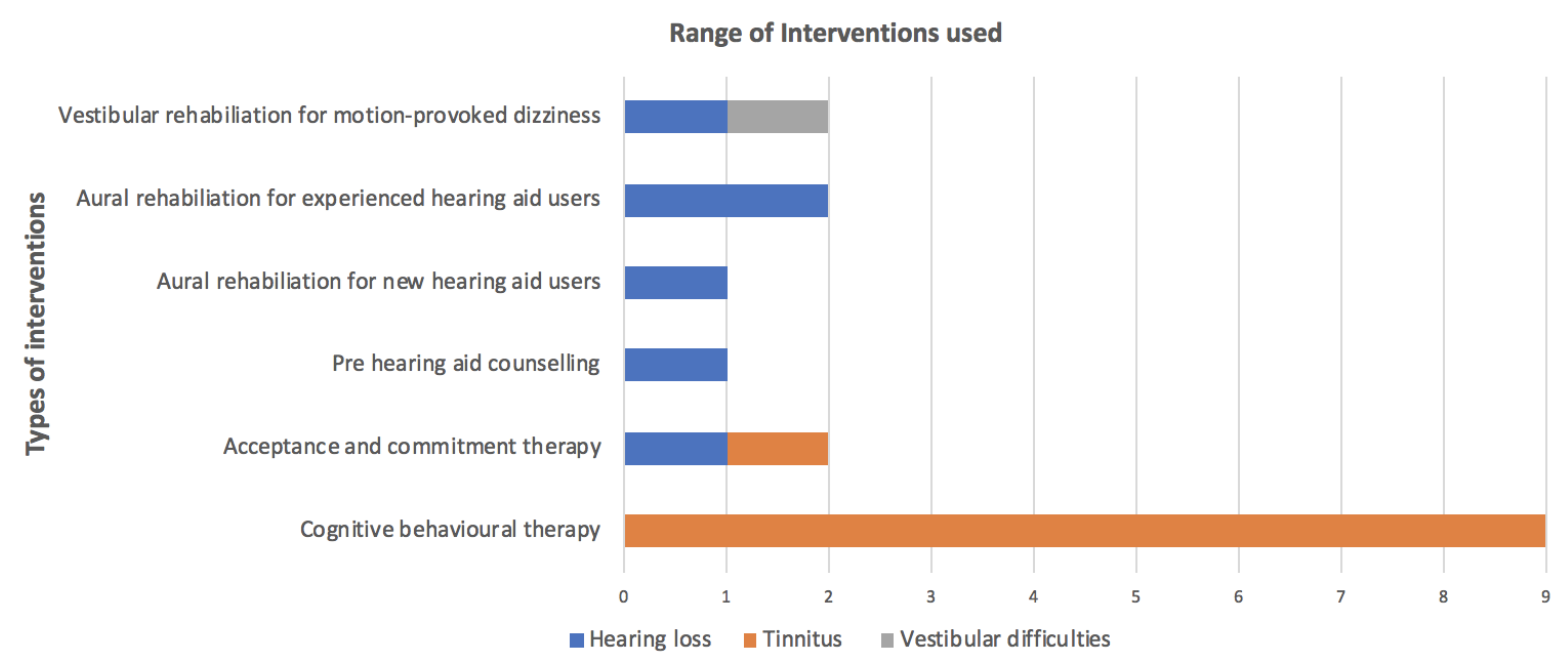

Figure 2: Types of comparator treatments used to evaluate the Internet-based interventions

\section{Range of comparators used}

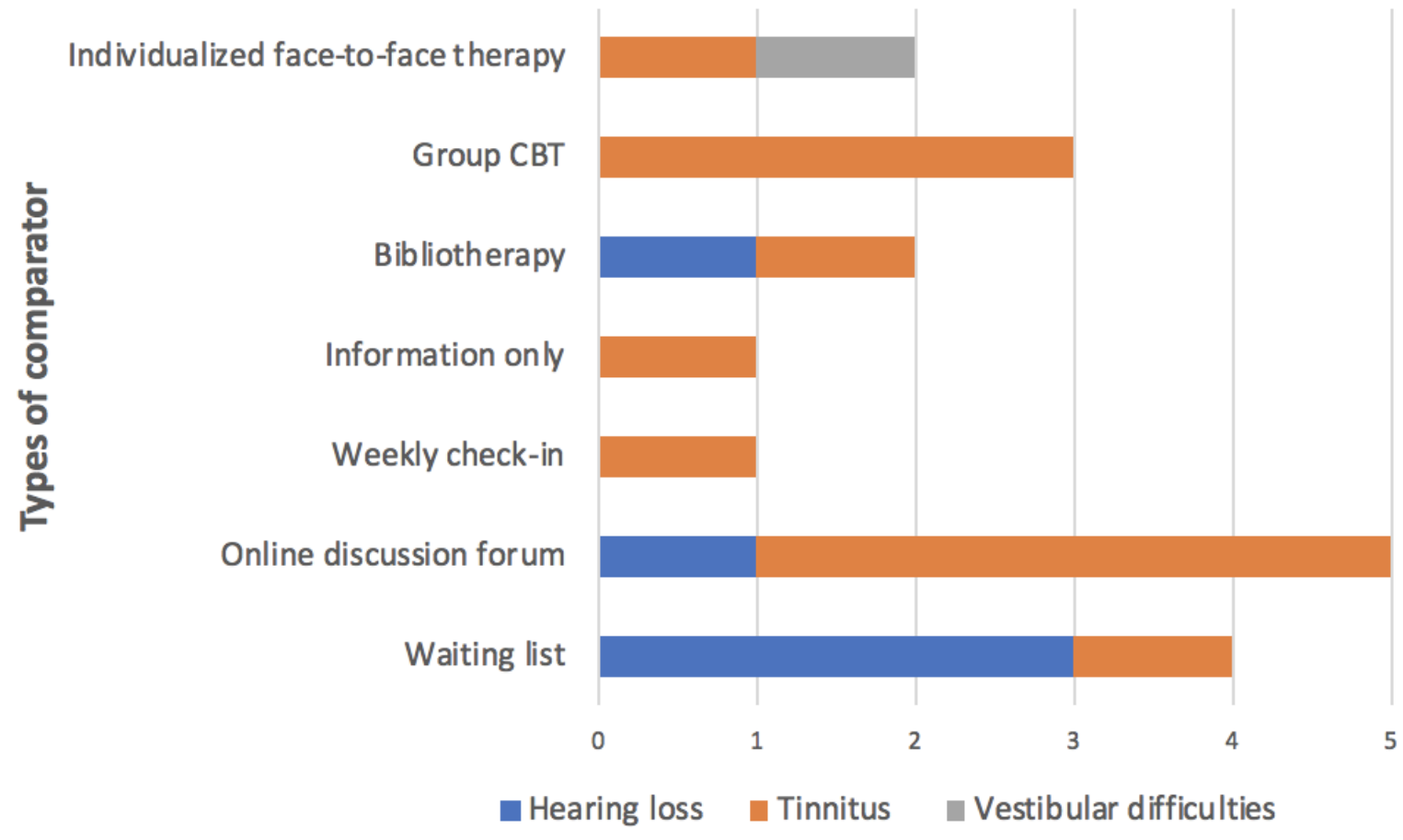

Table 1: Result comparison between the different types of Internet interventions

\begin{tabular}{|l|l|l|l|}
\hline $\begin{array}{l}\text { Type of } \\
\text { Intervention }\end{array}$ & Hearing loss & Tinnitus & $\begin{array}{l}\text { Vestibular } \\
\text { Disorders }\end{array}$ \\
\hline $\begin{array}{l}\text { Number of } \\
\text { included studies }\end{array}$ & Five $^{13-17}$ & Nine & One \\
\hline $\begin{array}{l}\text { Effect on hearing } \\
\text { loss, tinnitus and } \\
\text { dizziness tinnitus }\end{array}$ & $\begin{array}{l}\text { The pre-fitting study } \\
\text { showed no effect. If } \\
\text { removing this study }\end{array}$ & Moderate & $\begin{array}{l}\text { In this one } \\
\text { study, less }\end{array}$ \\
\hline
\end{tabular}




\begin{tabular}{|c|c|c|c|}
\hline & $\begin{array}{l}\text { there was a moderate } \\
\text { effect }\end{array}$ & & $\begin{array}{l}\text { self-reported } \\
\text { dizziness }\end{array}$ \\
\hline Effect on anxiety & Equivalent findings & Small & $\begin{array}{l}\text { Initial } \\
\text { reduction not } \\
\text { maintained }\end{array}$ \\
\hline $\begin{array}{l}\text { Effect on } \\
\text { depression }\end{array}$ & Small & Small & $\begin{array}{l}\text { Equivalent } \\
\text { findings }\end{array}$ \\
\hline $\begin{array}{l}\text { Effect on quality of } \\
\text { life }\end{array}$ & $\begin{array}{l}\text { Only evaluated in } 1 \\
\text { study indicating a } \\
\text { large effect }\end{array}$ & Equivalent findings & Not assessed \\
\hline Effect on insomnia & Not assessed & Small & Not assessed \\
\hline $\begin{array}{l}\text { Duration of post- } \\
\text { intervention } \\
\text { improvements } \\
\text { measured and } \\
\text { maintained }\end{array}$ & 6 months & 1 year & 6 months \\
\hline
\end{tabular}

\section{Is here evidence for IBI for hearing loss?}

Results indicated that IBI for hearing loss can be of great value, although further high-quality studies are required to improve the evidence base. The optimal IBI model for hearing loss needs consideration. This may be a blended approach, where hearing aids are fitted (face-toface, remotely or provided over the counter), and IBI provide the extensive auditory rehabilitation required. Further considerations are how to provide the varying rehabilitation needs that are required to address each stage of the hearing rehabilitation pathway to include pre-intervention counselling, post-fitting rehabilitation and addressing the emotional and functional effects. There is not always the time or expertise to address the psychological distress associated with hearing problems. IBIs are a very viable options for such help. Further development of these interventions may improve the possible additional effects such as improving quality of life.

\section{Is there evidence for IBI for tinnitus?}

The tinnitus IBI stood apart from the other interventions as a more unified approach was followed using the theoretical principles of CBT. Despite the proved effectiveness of CBT for tinnitus $^{28,29}$, its provision is often hampered as there are not many qualified professionals who can offer this support ${ }^{30}$. From the present review, CBT IBI for tinnitus indicated clear potential to improve access to evidence-based accessible interventions. They also contributed to assisting in reducing the various comorbidities such as insomnia, anxiety, depression and improving quality of life. The evidence base is further enhanced as results were maintained long term (i.e., measured up to one-year post-intervention). Further work should identify which aspects of these interventions should be modified to further improve the clinical significance impact they can have.

\section{Is there evidence for IBI for vestibular disorders?}

There is only one study included in the review that examined efficacy of IBI for vestibular disorders. From these findings it was clear that there is an immediate need to further develop IBI to address the various types of vestibular disorders. This study in this review addressed motion-provoked dizziness. Another IBI for Ménière's disease ${ }^{31}$ was identified but did not meet the inclusion criteria. Considering the high prevalence of different types of vestibular problems, IBI could significantly help address these difficulties. Many vestibular disorders require long term input which is not always possible due to a lack of clinical and financial 
resources. IBI could potentially relief the associated burden and provide rehabilitation to those without such opportunities at present.

\section{Implications of this review for HHC Professionals}

Due to the rising prevalence of hearing-related disorders, extensive HHC rehabilitation will be required. This provision is challenging due to time and resource limitations. This review has found that IBI's have the potential to improve accessibility and affordability of HHC, but require a wider and stronger evidence-base. IBI could play a clear role in providing comprehensive rehabilitation, which has been shown to improve outcomes and quality of life $^{33}$. The focus regarding the development of these interventions to date has been in Europe. There is an urgent need to adapt and assess the effects of IBI for different cultures and populations. The most efficient way to addressing these needs and reducing the impact of hearing-related difficulties, is a united approach. HHC professionals are uniquely positioned to advocate and implement changes to increase the provision of HHC across the globe ${ }^{32}$. This may be consideration to include IBI where access to service provision is limited, engagement in the rehabilitation process is required, and/or professional expertise is lacking. Once developed these IBI can be shared in areas were audiology services are particularly limited. IBI can thus unite professionals and provide standardized care, regardless of geographic location.

The greatest challenge will perhaps be getting these interventions implemented in clinical practice. Here again, HHC professionals can play a central role in advocating the inclusion of such interventions to stakeholders. IBI also provide numerous opportunities for promoting self-management in individuals with hearing-related conditions and to promote public-patient involvement, which could furthermore unite and strengthen service provision. In summary, although the evidence needs improving, IBI have clear potential in ensuring cost and clinically effective treatments and improving the global sustainability of audiological rehabilitation services.

\section{References}

1. Olusanya BO, Neumann KJ, Saunders JE. The global burden of disabling hearing impairment: A call to action. Bull World Health Organ. 2014;92:367-373.

2. Vos T, Allen C, Arora M, et al. Global, regional, and national incidence, prevalence, and years lived with disability for 310 diseases and injuries, 1990-2015: A systematic analysis for the global burden of disease study 2015. The Lancet. 2016;388(10053):1545-1602.

3. McCormack A, Edmondson-Jones M, Somerset S, Hall D. A systematic review of the reporting of tinnitus prevalence and severity. Hear Res. 2016;337:70-79.

4. Jönsson R, Sixt E, Landahl S, Rosenhall U. Prevalence of dizziness and vertigo in an urban elderly population. Journal of vestibular research. 2004;14(1):47-52.

5. Bainbridge KE, Wallhagen MI. Hearing loss in an aging american population: Extent, impact, and management. Annu Rev Public Health. 2014;35:139-152.

6. World Health Organization. World report on ageing and health. World Health Organization; 2015.

7. World Health Organization. Multi-country assessment of national capacity to provide hearing care, 2013.

8. Hignett S, Lang A, Pickup L, et al. More holes than cheese. what prevents the delivery of effective, high quality and safe health care in england? Ergonomics. 2018;61(1):5-14. 
9. Barnett M, Hixon B, Okwiri N, et al. Factors involved in access and utilization of adult hearing healthcare: A systematic review. Laryngoscope. 2017;127(5):11871194.

10. Donahue A, Dubno JR, Beck L. Guest editorial: Accessible and affordable hearing health care for adults with mild to moderate hearing loss. Ear Hear. 2010;31(1):2-6.

11. Yardley L, Spring BJ, Riper H, et al. Understanding and promoting effective engagement with digital behavior change interventions. Am J Prev Med. 2016;51(5):833-842.

12. Beukes EW, Manchaiah V, Allen PM, Baguley DM, Andersson G. Internet-based interventions for adults with hearing loss, tinnitus, and vestibular disorders: A systematic review and meta-analysis. Trends in hearing. 2019;23:2331216519851749.

13. Malmberg M, Lunner T, Kahari K, Andersson G. Evaluating the short-term and longterm effects of an internet-based aural rehabilitation programme for hearing aid users in general clinical practice: A randomised controlled trial. BMJ Open. 2017;7(5):e013047-2016-013047.

14. Manchaiah V, Rönnberg J, Andersson G, Lunner T. Use of the 'patient journey'model in the internet-based pre-fitting counseling of a person with hearing disability: Lessons from a failed clinical trial. BMC Ear, Nose and Throat Disorders. 2014;14(1):3.

15. Molander P, Hesser H, Weineland S, et al. Internet-based acceptance and commitment therapy for psychological distress experienced by people with hearing problems: A pilot randomized controlled trial. Cognitive behaviour therapy. 2018;47(2):169-184.

16. Thorén E, Svensson M, Törnqvist A, Carlbring P, Lunner T. Rehabilitative online education versus internet discussion group for hearing aid users: A randomized controlled trial. J Am Acad Audiol. 2011;22(5):274-285.

17. Thorén ES, Öberg M, Wänström G, Andersson G, Lunner T. A randomized controlled trial evaluating the effects of online rehabilitative intervention for adult hearing-aid users. International Journal of Audiology. 2014;53(7):452-461.

18. Beukes EW, Baguley DM, Allen PM, Manchaiah V, Andersson G. Audiologistguided internet-based cognitive behavior therapy for adults with tinnitus in the united kingdom: A randomized controlled trial. Ear Hear. 2018;39(3):423-433.

19. Hesser H, Gustafsson T, Lunden C, et al. A randomized controlled trial of internetdelivered cognitive behavior therapy and acceptance and commitment therapy in the treatment of tinnitus. J Consult Clin Psychol. 2012;80(4):649-661.

20. Jasper K, Weise C, Conrad I, Andersson G, Hiller W, Kleinstaeuber M. Internetbased guided self-help versus group cognitive behavioral therapy for chronic tinnitus: A randomized controlled trial. Psychother Psychosom. 2014;83(4):234-246.

21. Nyenhuis N, Kröner-Herwig B, Zastrutzki S, Jäger B. An internet- based cognitivebehavioural training for acute tinnitus: Secondary analysis of acceptance in terms of satisfaction, trial attrition and non-usage attrition. Cognitive Behaviour Therapy. 2013;42(2):139-145.

22. Weise C, Kleinstauber M, Andersson G. Internet-delivered cognitive-behavior therapy for tinnitus: A randomized controlled trial. Psychosom Med. 2016;78(4):501510.

23. Beukes, E.W., Andersson, G., Allen, P.M. Manchaiah, V. and Baguley, D.M. Effectiveness of guided internet-based cognitive behavioural therapy vs face-to-face clinical care for treatment of tinnitus. A randomized clinical trial. JAMA Otolaryngology-Head \& Neck Surgery. 2018;144(12):1126-1133. 
24. Kaldo V, Levin S, Widarsson J, Buhrman M, Larsen H, Andersson G. Internet versus group cognitive-behavioral treatment of distress associated with tinnitus: A randomized controlled trial. Behavior Therapy. 2008;39(4):348-359.

25. Beukes EW, Allen PM, Baguley DM, Manchaiah V, Andersson G. Long-term efficacy of audiologist-guided internet-based cognitive behavior therapy for tinnitus. Am J Audiol. 2018;27(3S):431-447.

26. Andersson G, Stromgren T, Strom L, Lyttkens L. Randomized controlled trial of internet-based cognitive behavior therapy for distress associated with tinnitus. Psychosom Med. 2002;64(5):810-816.

27. Geraghty AWA, Essery R, Kirby S, et al. Internet-based vestibular rehabilitation for older adults with chronic dizziness: A randomized controlled trial in primary care. Ann Fam Med. 2017;15(3):209-216.

28. Hoare DJ, Kowalkowski VL, Kang S, Hall DA. Systematic review and meta-analyses of randomized controlled trials examining tinnitus management. Laryngoscope. 2011;121(7):1555-1564.

29. Martinez-Devesa P, Perera R, Theodoulou M, Waddell A. Cognitive behavioural therapy for tinnitus. The Cochrane Library. 2010.

30. Schmidt CJ, Kaelin C, Henselman L, Henry JA. Need for mental health providers in progressive tinnitus management: A gap in clinical care. Federal Practitioner. 2017;34(5):6.

31. Pyykkő I, Manchaiah V, Kentala E, Levo H, Juhola M. Internet-based self-help for ménière's disease: Details and outcome of a single-group open trial. Am J Audiol. 2017;26(4):496-506.

32. Brodie A, Smith B, Ray J. The impact of rehabilitation on quality of life after hearing loss: A systematic review. European Archives of Oto-Rhino-Laryngology. 2018;275(10):2435-2440.

33. O'Donoghue GM, Tucci DL, Wilson BS. The mounting burden of hearing loss worldwide: Gearing up global collaboration. ENT \& Audiology News. 2017;26:65-66.

\section{Autor Bio's}

Dr. Beukes, left, is a post-doctoral researcher in the department of speech and hearing sciences at Lamar University in Beaumont, TX, where Dr. Manchaiah is the Jo Mayo Endowed Professor of Speech and Hearing Sciences.

\section{Correspondence}

Email: ebeukes@lamar.edu

Tel: +1 (409) 8808927

\section{Author Headshots}

Attached 